\title{
Electrophysical Apparatus for Intensifying the Production of High-Viscosity Oils
}

\section{Ponomarenko AG*}

Moscow Engineering Physics Institute, National Research Nuclear University, Russia

*Corresponding author: Alexey Ponomarenko, Moscow Engineering Physics Institute, National Research Nuclear University, Russia, Moccow 115409, Tel: 8(916)9138679; E-mail: AGPonomarenko@mephi.ru

\section{Investigation Paper}

Volume 4 Issue 1

Received Date: December 23, 2019

Published Date: January 29, 2020

DOI: $10.23880 /$ ppej-16000214

\section{Abstract}

The production of heavy high-viscosity oils is associated with the formation of asphalt-resin-paraffin deposits in the pipelines of the wells, which leads to a rapid decrease in their flow rate. Currently, a variety of mechanical, chemical, thermal and combined sediment removal tools are used in oilfield practice. Nevertheless, there remains a request for the search for new technological solutions that would allow environmentally sound removal of deposits without interruptions in the process of oil production with minimal energy and labor. This article reports on the first results of developing a new technology for removing deposits from well pipes, which is based on their non-contact local induction heating. At the contact point of the deposits with the heated section of the pipe, their partial melting occurs, as a result of which the bulk of the deposits in the form of large fragments is removed together with the oil flow. The inductor moves slowly along the axis of the well, receiving a high-frequency current from a nearby immersed energy converter.

Keywords: Asphalt-resin-paraffin deposits; Induction heater; High viscosity oil; Energy converter

\section{Introduction}

In the period from 2015 to 2019, a group of employees of Moscow Engineering Physics Institute carried out research work on the instructions of the Russian Science Foundation No. 15-19-00151 and 15-19-00151-P, the main scientific problem of which was the development of new technologies for heavy oils production intensification. Unlike ordinary oil, heavy oil is characterized by high viscosity and density; it contains in its composition clusters consisting of sulfur atoms and various metals. The process of producing highviscosity oils is complicated by the formation of asphaltresin-paraffin deposits (ARPD) in the pipelines of the wells, which leads to a rapid decrease in their flow rate and forces to interrupt the production process during repair and restoration procedures. Another problem is that the bottomhole zone of heavy oil wells has low permeability and special methods should be used to extract it.

Studies were carried out by us in both of these directions, however, in our opinion, we were able to achieve the best results in terms of removing paraffin deposits from inside the tubing and casing of wells without interruptions in the process of oil production by a mechanized method. Our proposed electrophysical technology for removing paraffin deposits is described in a series of articles published in 2019 by the journal Chemical and Oil and Gas Engineering [1-3]. The purpose of this publication is to critically analyze the results and determine the future direction of work on the project. 


\section{Petroleum \& Petrochemical Engineering Journal}

\section{Physical Basis of the Proposed Technology}

The technology is based on the principle of non-contact heating of a short $(15-20 \mathrm{~cm})$ pipe section with a current induced therein at a frequency of about $20 \mathrm{kHz}$. Flowing, as in a short-circuited turn, in the surface skin layer of a steel pipe, he heats it with a power of $\sim 10^{3} \mathrm{~W}$ with induced current amplitude of 300-700 A. This is achieved by creating a strong, rapidly changing magnetic field at the pipe walls using a multi-turn inductor winding, fed by a current of a specified frequency from an energy converter [1]. These requirements can be realized if reactive energy exchange of $\sim 10^{4}$ VAR is provided between the inductor and the converter. In this case, the converter and inductor should be located no further than 10-20 $\mathrm{m}$ from one another [2].

One of the possible options for the electrophysical technology for removing paraffin deposits is that at the same time as pumping the produced oil through the tubing to the wellhead, the "converter-inductor" process pair slowly drops on the load-bearing cable in the gap between the tubing and the casing of the well. In this case, the converter supplies the inductor with a high-frequency current, which is generated due to direct current energy of about $300 \mathrm{~V}$ supplied from the Earth's surface. Since the inductor winding covers the tubing, a strong high-frequency magnetic field is formed in the gap between it and the outer surface of the tubing, the energy of which is partially spent on heating of the tubing, see the scheme in Figure 1.

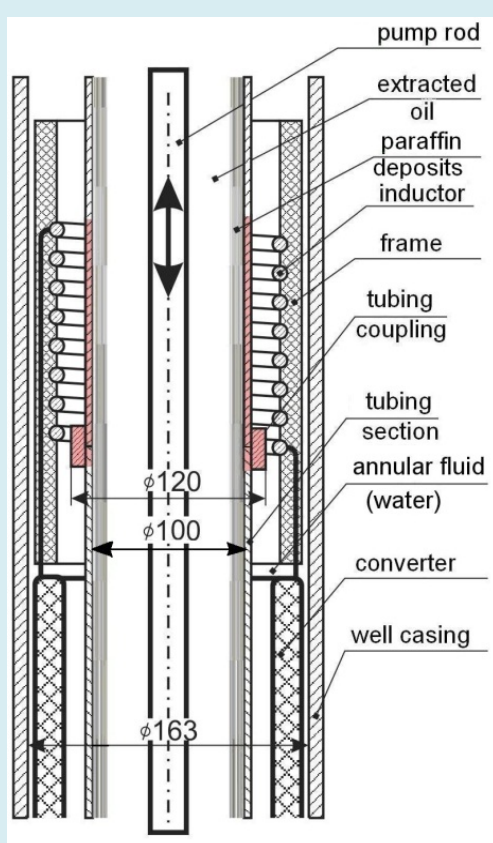

Figure 1: Scheme removal of paraffin from inside tubing $\varnothing 100 \mathrm{~mm}$ in a well with casing $\varnothing 163 \mathrm{~mm}$ by the method of local induction heating.
The heating power (1-3 kW) is released locally on a short pipe section, the length of which is close to the axial size of the inductor winding. Intensive melting of the paraffin occurs at the point of contact of the inner surface of the tubing with the paraffin deposits layer. Thus, the main part of the ARPD remaining in the solid phase in this area is deprived of a retaining bond with the pipe. Fragments of deposits are separated from the tubing and in the form of "rags" along with the oil flow are delivered to the wellhead.

The heated pipe section is highlighted in color.

The natural physical root cause of the formation of paraffin deposits is the decrease in pressure experienced by the oil during its successive movement from the oil reservoir, first into the casing, then into the elevator pipe and inside it rise to the wellhead, to the Earth's surface. At all stages, this is accompanied by the separation of light fractions, which, passing into a gaseous form, inevitably lower the temperature of the oil and, as a result, provoke the precipitation of heavy fractions. A common drawback of modern methods of combating the formation of paraffin deposits is that they are focused on opposing the described natural process. Specifically, chemical methods by dissolving deposits or reducing their adhesion to the walls of the tubing, thermal methods by heating the mass of produced oil when the curing temperature is not reached right up to the wellhead, mechanical methods by completely or partially dismantling the pipeline, followed by heating of its parts, etc. At the same time, energy, financial and labor expenses, as well as environmental problems, increase so much that heavy high-viscosity oils are compelled to be classified as hard to recover.

The main difference of the proposed electrophysical technology is the fact that the formation of paraffin deposits on the inner wall of the tubing is regarded as a useful stage in the production process. The heavy fractions of the produced oil go into the solid phase that is natural for them on the surface of the Earth. The extracted oil flows to the wellhead in the form of a mixture of solid fragments with a liquid mass. They are easy to separate here. The liquid part, freed from high molecular weight components, has reduced its viscosity, now it can be transported by pipeline or in tanks. Solid components (paraffins, bitumen, etc.) can be transported in containers.

The proposed electrophysical technology for the removal of paraffin deposits can also be applied in the case where the technological pair "Converter-inductor" is inside the pipe being processed. This configuration can be demanded when removing paraffin from the inner surface of the casing in the area of its contact with the oil reservoir through the perforations. In Dmitriev MS, et al. [3] it was shown, that from the point of view of energy efficiency of the ARPD removal 


\section{Petroleum \& Petrochemical Engineering Journal}

process, this case is the most unfavorable, since most of the heat released during heating is transferred from the pipe to the surrounding formation. However, with a heating power of $3 \mathrm{~kW}$ and an inductor moving speed of $5 \mathrm{~cm} / \mathrm{min}$, the ARPD particles located on the inner surface of the pipe $(\mathrm{R}=$ $8 \mathrm{~cm}$ ) are in a liquid state on a section about $15 \mathrm{~cm}$ long for 3 minutes. In this mode, it will take about 3.5 hours to clear the paraffin deposits of the casing section with a length of $10 \mathrm{~m}$. The device power supply Converter, which may be in demand in this application, is described in article Klachkov AP, et al. [4].

\section{Analysis of the Results of the First Stage and Tasks for the Future}

In our opinion, the presented results can be considered as a successful completion of the first stage of the task. The technical solutions underlying the proposed electrophysical technology were worked out in detail and tested on laboratory mock-ups. In particular, experimentally confirmed:

1. High efficiency of a half-bridge converter of direct current energy into alternating current in the mode of intensive energy exchange with inductive-resistive load; 2. High efficiency induction heater of the proposed design; 3. The possibility of autonomous operation of control electronics, including in the configuration of the converter for operation at great depths in the space between tubing and casing.

The last of these results was achieved at the end of the research. On the whole, the data obtained confirm the validity and feasibility of the concept of electrophysical technology, which was presented by us earlier in article Bogdanovich Byu, et al. [1]. Now we are convinced that the results obtained are sufficient to open up a comprehensive experimental design work for the manufacture and downhole testing of prototypes of oilfield equipment for the production of heavy and highly viscous oils. In the course of these works, it will be necessary to solve the applied problems of developing equipment for the wellhead, bottom hole and elevator facilities of wells using electrophysical oil production technology.

At the same time, it is necessary to refine the samples of the inductor and its power system in order to ensure reliable and long-term operation in the conditions of a real oil field. At the previous stage, we, of course, preliminarily worked out the issues of cooling, mechanical strength, controllability of electrophysical equipment, etc. The accumulated experience gives us justified hope that these goals are achievable, and electrophysical technology as a whole will prove its economic feasibility.

\section{Conclusion}

During the first stage of work, we were convinced that our idea creates prospects for a significant improvement in the infrastructure for the production of high-viscosity oil. Along with overcoming a number of existing problems in production, it will make it possible to obtain oil at the outlet in separated form, which will facilitate its further transportation.

\section{Acknowledgments}

With great warmth I thank my friends: A.P. Klachkov and M.S. Dmitriev - for their personal contribution to the joint search for solutions, V.V. Yanenko - for invaluable help in preparing the experiments. My deep bow to the Department of Plasma Physics, headed by V.A. Kurnaev - for friendly sympathy and organizational assistance.

\section{References}

1. Bogdanovich BYu, Shikanov AE, Dmitriev MS, Ponomarenko AG, Klachkov AP, et al. (2019) Electrophysical concept of the technology for removing of asphalt-resin-paraffin deposits from well pipes in the continuous production of high-viscosity oils. Chemical and Oil and Gas Engineering 7: 9-11.

2. Klachkov AP, Ponomarenko AG (2019) Submersible highfrequency power generator for the removal of asphaltresin-paraffin deposits from well pipes in the mode of continuous production of high-viscosity oils. Chemical and Oil and Gas Engineering 9: 31-34.

3. Dmitriev MS, Ponomarenko AG, Klachkov AP (2019) Thermophysical substantiation of the technology for removing asphalt-resin-paraffin deposits from well pipes in the mode of continuous production of highviscosity oils. Chemical and Oil and Gas Engineering 8: 11-14.

4. Klachkov AP, Ponomarenko AG (2018) Submersible generator for power supply of the system of thermal and ultrasonic impact on the bottom hole formation zone. Nuclear Physics and Engineering 9(4): 366-370. 